\title{
IgG subclass response and protection against challenge following immunisation of mice with various influenza $A$ vaccines
}

\author{
E. T. S. BEN-AHMEIDA, C. W. POTTER, G. GREgORIADIS*, C. ADITHAN $\dagger$ and R. JENNINGS $\ddagger$
}

Department of Experimental and Clinical Microbiology, University of Sheffield Medical School, Beech Hill Road, Sheffield S10 2RX, * Centre for Drug Delivery Research, The School of Pharmacy, University of London, 29/39 Brunswick Square, London WC1N 1 AX and † Department of Pharmacology, Jawaharlal Institute of Postgraduate Medical Education and Research, Pondicherry, India

\begin{abstract}
Summary. The serum total IgG and IgG subclass and nasal wash $\operatorname{IgA}$ and $\operatorname{IgG}$ antibody responses of mice to influenza virus A/Hong Kong/68 (H3N2) subunit preparations administered parenterally as a single dose, incorporated either in immune stimulatory compounds (ISCOMs) or liposomes with Freund's Complete Adjuvant, or as an aqueous material, as well as to live, infectious virus were measured by ELISA at 10 days and 3, 5, 7 and 22 weeks after immunisation. The protection of the upper and lower respiratory tracts provided by these preparations against homologous and heterologous challenge infection was assessed. Of the four variously-presented subunit preparations, influenza subunit ISCOMs induced relatively high and persisting levels of each of the different IgG subclasses, particularly IgG2a, throughout the study, and most nearly approached those observed after intranasal infection of mice with infectious virus. Furthermore, nasal wash IgA and IgG antibody levels, particularly at 5 or 7 weeks after immunisation, were also significantly greater in mice given the subunit ISCOM preparation than those induced by other subunit preparations with adjuvant or subunits given alone, and provided protection of both the upper and lower respiratory tracts against challenge as similar to that elicited by infectious virus.
\end{abstract}

\section{Introduction}

The development of inactivated influenza vaccines has evolved from whole virus vaccines to split vaccines to subunit vaccines with diminishing reactogenicity. ${ }^{1}$ In contrast, protection against challenge infection conferred by all these vaccines remains disappointing, with rates of $60-90 \% .^{2,3}$ By the introduction of molecular biological techniques, larger quantities of viral haemagglutinin (HA) may be available for immunisation, but vaccines with increased HA content may be more reactogenic, since HA is intrinsically pyrogenic, ${ }^{4}$ without conferring better immunity. One approach may be the use of vaccines better matched to epidemic strains, and preliminary results suggest that this may come from virus vaccines grown in tissue culture..$^{5}$ An alternative could be to amplify the immune responses to small quantities of virus HA by immunisation in conjunction with biological modifiers; ${ }^{6}$ to this end, several amplifying systems have been suggested, including liposomes, ${ }^{7}$ muramyl dipeptides $^{8,9}$ and immune stimulatory compounds
(ISCOMs). ${ }^{10,11}$ Compared to saline vaccines, these and other adjuvanted vaccines have been shown to enhance the immune responses and provide protection against challenge infection in animal studies. However, comparisons of different amplifying strategies have not been carried out with the same rigour, and many of these systems do not induce as solid an immunity as that seen following live virus infection. ${ }^{12,13}$

In the present study, the antibody responses to immunisation with live influenza virus or inactivated saline vaccine were compared with the responses induced by subunit vaccines with the different amplifying systems. Nasal wash IgG and IgA and serum total IgG and IgG subclass antibodies were measured at various times after immunisation, and protection against both homologous and heterologous virus infection was determined. The studies were performed to identify, in comparative studies, the best amplifying system producing protection against challenge virus infection in mice, and to assess the role of subclass IgG antibodies in this protection. The work is part of a wider study of the use of biological modifiers for influenza virus vaccines. 


\section{Materials and methods}

\section{Viruses}

Influenza virus A Hong Kong/68(H3N2) was cultured in the allantoic cavities of 10-day embryonated hens' eggs incubated at $33^{\circ} \mathrm{C}$ for $72 \mathrm{~h}$. After incubation, allantoic fluids were harvested, pooled, centrifuged at $4000 \mathrm{~g}$ for $15 \mathrm{~min}$ and the supernate was then centrifuged at $30000 \mathrm{~g}$ for $2 \mathrm{~h}$. The pellet was resuspended in phosphate-buffered saline (PBS), $\mathrm{pH}$ $7 \cdot 2$, layered on to a $10-60 \%$ sucrose density gradient and centrifuged at $30000 \mathrm{~g}$ for $90 \mathrm{~min}$ at $4^{\circ} \mathrm{C}$. Density gradient fractions containing the highest titres of HA were pooled, concentrated by centrifugation at $30000 \mathrm{~g}$ for $2 \mathrm{~h}$ and resuspended in $2.0 \mathrm{ml}$ of PBS. Neuraminidase (NA) and HA suspension was prepared by treating purified virus suspensions with the zwitterionic detergent Empigen BP (Albright and Wilson Ltd, Whitehaven, Cumbria), as described previously. ${ }^{14}$ The resulting lysate was dialysed against PBS for 3 days at $4^{\circ} \mathrm{C}$, layered on to a $10-60 \%$ sucrose density gradient, centrifuged at $30000 \mathrm{~g}$ for $90 \mathrm{~min}$ at $4^{\circ} \mathrm{C}$ and the fractions containing the highest titres of HA were pooled. The pool was centrifuged at $30000 \mathrm{~g}$ for $90 \mathrm{~min}$, resuspended in PBS and the HA content determined by single radial diffusion, ${ }^{15}$ with standard antigens and antisera kindly supplied by $\mathrm{Dr}$ J. Wood (National Institute of Biological Standards and Control, Potters Bar, Herts). Protein concentrations were estimated by the method of Bradford. ${ }^{16}$

Infective pools of influenza viruses $\mathrm{A} / \mathrm{HK} / 68$ (H3N2), and A/Sichuan/87 (H3N2) were prepared in the allantoic cavities of 10-day embryonated eggs, as described above. The infectivity of these viruses for mice was calculated by intranasal inoculation of $0.1 \mathrm{ml}$ of virus dilutions in groups of three mice: 3 days later, individual mouse nasal washes and lung homogenates were tested for the presence of virus by egg inoculation, and the $50 \%$ mouse infective dose $\left(\mathrm{MID}_{50}\right)$ was calculated.

\section{Animals}

All vaccine studies were performed in female BALB/c mice obtained from a closed colony at the University of Sheffield; at the time of the experiments, mice were 6-8 weeks old and weighed $20-25 \mathrm{~g}$.

\section{Virus vaccines}

Groups of mice were infected with live virus or given one of four inactivated virus vaccines. Mice infected with live virus received $10^{3.0} \mathrm{MID}_{50}$ of virus intranasally, dropwise in $0.1 \mathrm{ml}$ of PBS. The vaccinated groups of mice were inoculated intramuscularly with aqueous subunit vaccine containing $0.25 \mu \mathrm{g}$ of HA, $0.25 \mu \mathrm{g}$ of HA incorporated into ISCOMs with the glycoside Quil A (kindly supplied by Dr B. Morein, National Veterinary Institute, Division of Vaccine Research, Uppsala, Sweden), and prepared as de- scribed previously, ${ }^{11} 0 \cdot 25 \mu \mathrm{g}$ of HA incorporated into liposomes by procedures described previously, ${ }^{12,17}$ or PBS. A final group was inoculated subcutaneously with $0.25 \mu \mathrm{g}$ of subunit vaccine mixed with an equal volume of Freund's Complete Adjuvant (FCA; Sigma). In each case, vaccines or PBS were given in $0 \cdot 2-\mathrm{ml}$ volumes.

\section{Immunisation and virus challenge}

A total of 198 unprimed mice were used. The first experiment was performed in six groups of 18 mice; four groups received $0.25 \mu \mathrm{g}$ of HA in saline, FCA, liposomes or ISCOMs, and the other two groups received either PBS alone, or were inoculated intranasally with $10^{3 \cdot 0} \mathrm{MID}_{50}$ of live virus in a $0 \cdot 1-\mathrm{ml}$ volume. Serum samples were obtained from each mouse at 10 days, and 3,7 and 22 weeks after immunisation and tested for total IgG antibodies. The serum samples collected at 3,7 and 22 weeks were also tested for IgG subclass antibody levels. One day after collection of sera at 3, 7 and 22 weeks, five mice from each group were challenged by intranasal inoculation with $10^{3 \cdot 0} \mathrm{MID}_{50}$ of live influenza virus $\mathrm{A} /$ Hong $\mathrm{Kong} / 68$; these mice were killed 3 days after inoculation, and the lungs and nasal washings were tested for the presence of virus. The nasal washes were also assayed for IgA and total IgG antibodies.

In a separate experiment, five groups of 18 mice received the same vaccine schedule as above, excluding the liposome-treated group. Serum samples from each mouse were collected 5 weeks after immunisation and assayed for total IgG and IgG subclass antibody.

One day after this, six mice in each group were challenged with $10^{3 \cdot 0} \mathrm{MID}_{50}$ of homologous $\mathrm{A} / \mathrm{HK} / 68$ virus or the heterologous influenza $\mathrm{A} /$ Sichuan $/ 87$ virus strain, as described above. Three days after challenge infection, nasal washes and lung homogenates were tested for the presence of virus; the nasal washes were also assayed for $\operatorname{IgA}$ and total $\operatorname{IgG}$ antibody.

\section{Virus isolation}

Virus isolations were performed as described previously. ${ }^{11,18}$

\section{Serological tests}

The enzyme-linked immunosorbent assay (ELISA) method was used to measure total IgG and subclass $\operatorname{IgG}$ antibody in mouse sera, and IgA and total IgG in nasal washings. Several mice from each group were selected at random and bled before the experiment and these sera were also tested to provide a baseline control; no antibody was detected in them.

ELISA for serum antibody against influenza viruses was performed as described previously..$^{19}$ Briefly, wells of ELISA microtitration plates (Nunc, Life Technology, Paisley) were each coated with $3 \mu \mathrm{g}$ of purified, 


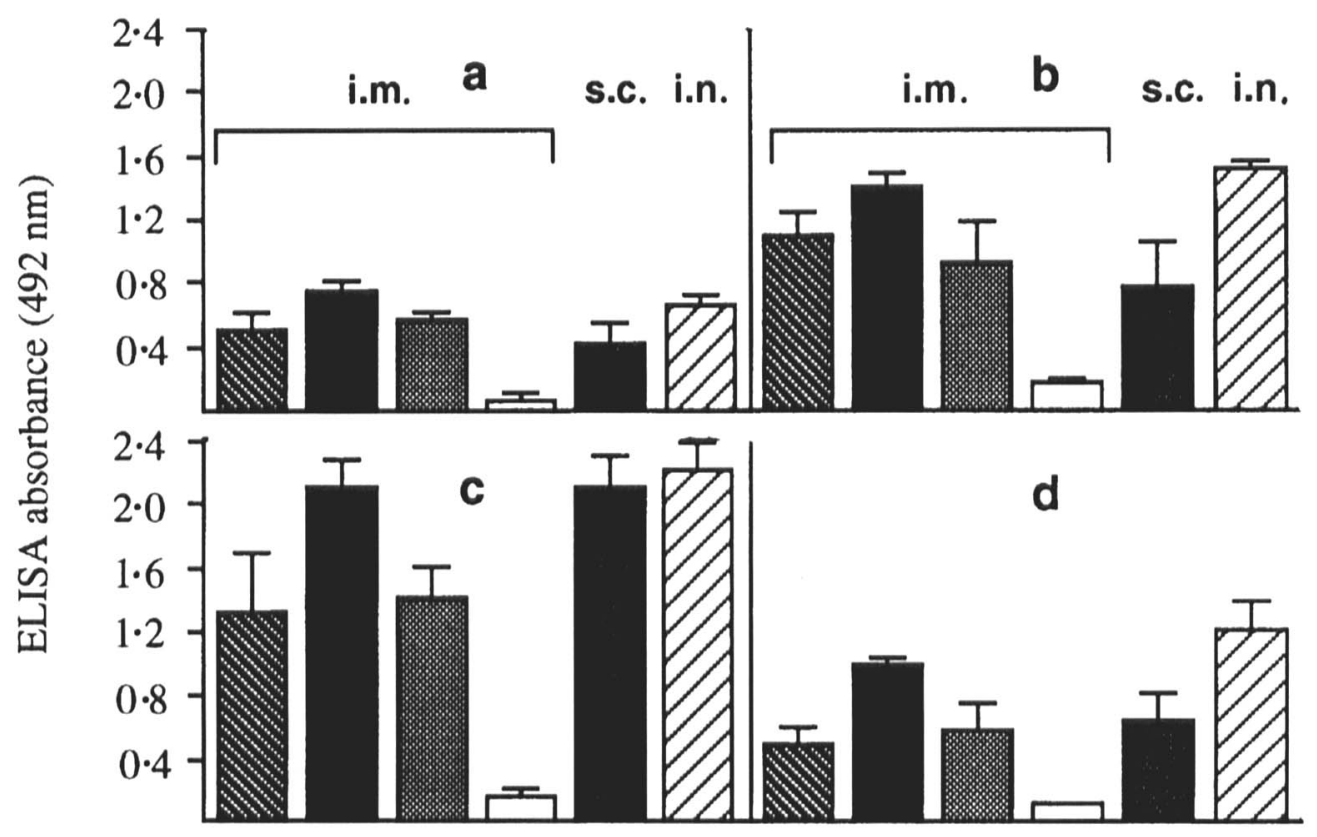

Fig. 1. IgG antibody levels in sera of mice immunised with influenza A/HK/68 subunit antigen alone, incorporated with liposomes, ISCOMs or FCA, or given live virus: i.n., intranasal; i.m., intramuscular; s.c., subcutaneous inoculation. Subunit antigens in liposomes; subunit antigens in ISCOMs; $\square$ subunit antigens alone; $\square$ PBS; $\square$ subunit antigens with FCA; $\square$ A/Hong Kong live virus. a, 10 days postimmunisation; b, 3 weeks p.i.; c, 7 weeks p.i.; d, 22 weeks p.i.

whole $\mathrm{A} / \mathrm{HK} / 68$ antigen in $200 \mu \mathrm{l}$ of carbonate buffer, pH 9.6. After $24 \mathrm{~h}$ at $4^{\circ} \mathrm{C}$, the plates were washed three times with Tween-20 0.05\% v/v in PBS (PBS-Tween), and undiluted nasal wash (for IgG determination only) or serum diluted in PBS-Tween plus BSA $1 \%$ was added to wells in triplicate; the plates were then incubated for $1 \mathrm{~h}$ at $37^{\circ} \mathrm{C}$. The wells were washed three times with PBS-Tween and treated with goat antimouse total IgG or IgG subclass antibody conjugated to horseradish peroxidase (Sigma) at optimal dilutions, as determined in previous experiments. After incubation for $1 \mathrm{~h}$ at $37^{\circ} \mathrm{C}$, the wells were washed three times with PBS-Tween, and $o$-phenylene-diamine substrate in citrate-phosphate buffer ( $\mathrm{pH} 5.0$ ) was added. After incubation for $30 \mathrm{~min}$ in the dark at room temperature, the reaction was stopped by the addition of $50 \mu \mathrm{l}$ of $2 \mathrm{~N} \mathrm{H}_{2} \mathrm{SO}_{4}$ and the absorbance was read at $492 \mathrm{~nm}\left(\mathrm{~A}_{492}\right)$.

Nasal wash IgA antibodies were also measured by an ELISA technique. This has been described in detail previously ${ }^{11}$ and is modified from procedures reported by Hocart $e t a .^{20}$

\section{Statistical analysis}

Comparisons between mouse groups with respect to the incidence and levels of serum and nasal washing antibody were made by the Mann-Whitney U-test.

\section{Results}

\section{Total serum IgG response to infection or immunisation}

Six groups of mice were given live A/HK/68 virus, aqueous subunit vaccine, or virus subunits incorporated with FCA, liposomes or ISCOMs, or PBS; serum samples were collected at 10 days, and 3,7 and 22 weeks post-immunisation (p.i.), and tested for IgG antibody responses. The results are shown in fig. 1. At 10 days, relatively low levels of IgG antibody were detected in all groups which received live virus or virus vaccines, and the levels were similar (fig. 1a). However, at 3 weeks p.i. (fig. 1b), higher total IgG antibody responses were recorded with the highest levels in mice given live virus or immunised with ISCOM vaccine; these levels were significantly greater than those in mice given other forms of vaccine $(p<0.01)$. At 7 weeks p.i., total IgG antibody levels had increased further (fig. 1c) with the highest levels observed in mice that received live virus or the subunit preparations formulated with ISCOMs or FCA; these levels were significantly higher than those for mice immunised with the aqueous or liposome vaccines $(p<0.01)$. Total IgG antibody levels declined in all immunised groups after this time (fig. 1d), and at 22 weeks the levels were similar to those seen at 10 days; nevertheless, total IgG antibody levels in mice that received ISCOM vaccine or live virus infection were significantly higher than in those given the other preparations $(\mathrm{p}<0.01)$. The results indicate that although the same pattern of rise and fall of antibody levels over the 22 weeks of observation was similar in all groups, higher antibody levels were achieved after immunisation with ISCOMs or infection with live virus and these remained high at 22 weeks.

\section{Serum IgG subclass responses to infection or immunisation}

Serum IgG subclass antibody responses were measured in all serum samples collected at 3, 7 and 22 weeks p.i. The results are shown in fig. 2 . There was a marked 


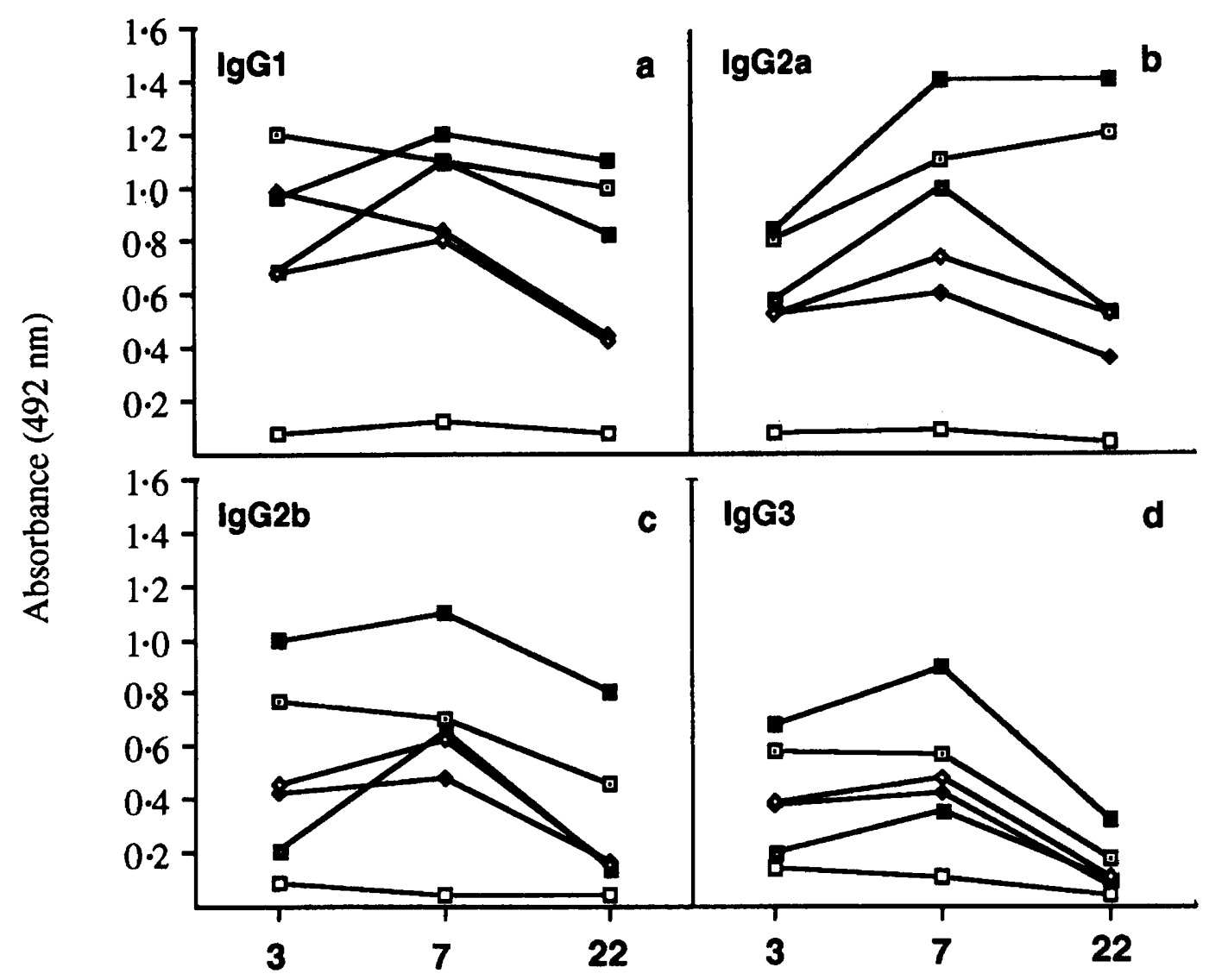

Weeks after immunisation

Fig. 2. Serum IgG subclass antibody responses of mice to immunisation with influenza $A / H K / 68$ subunit preparations or live virus. $\longrightarrow$ Subunits with ISCOMs; $-\longrightarrow$ subunits with liposomes; $-\mathbf{-}-$ subunits with FCA; $-\diamond-$ subunits alone;

IgG1 antibody response in all groups immunised with the various vaccine preparations or given live virus at 3 weeks p.i., which was significantly greater $(\mathrm{p}<0.01)$ in animals that had received the influenza $\mathrm{A} / \mathrm{HK} / 68$ subunit ISCOM preparation than in all other groups (fig. 2a). However, at 7 weeks p.i., the highest IgG1 antibody levels were observed in animals given live virus or the subunit ISCOM or FCA preparations. At 22 weeks p.i., IgG1 antibody levels had decreased in all groups, although relatively high levels persisted in mice immunised with the subunit ISCOM preparation or given live virus.

IgG2a subclass antibody responses were greatest at 3 weeks in those mice given live virus or virus subunits incorporated into ISCOMs (fig. 2b); however, the subsequent pattern for IgG2a antibody levels differed, depending on the immunising agents used. Thus, peak levels were observed at 7 weeks p.i. in mice given A/HK/68 subunits together with FCA, in a liposome formulation or as an aqueous preparation. However, those groups of animals that had received live virus or virus subunits incorporated into ISCOMs, although showing high levels of IgG2a subclass at 7 weeks p.i., also showed at least equally high levels at 22 weeks, with no sharp decline of this antibody at this time (fig. 2b). At both 7 and 22 weeks, the levels of IgG2a antibody in these two groups of animals were sig- nificantly greater than those observed in all other groups ( $\mathrm{p}<0.01$ ). However, at both times, the IgG2a levels achieved were significantly greater in the group given live virus than in that given the ISCOM preparation $(\mathrm{p}<0 \cdot 01)$.

The serum antibody responses of mice with regard to the IgG2b subclass was similar to that observed for IgG1 (fig. 2c), with levels as high at 3 weeks as at 7 weeks p.i. for most preparations. However, as for IgG1 (and IgG2a), the response to $\mathrm{A} / \mathrm{HK} / 68$ subunits administered with FCA was relatively low at 3 weeks, peaked sharply at 7 weeks and declined considerably at 22 weeks. Significantly greater $(p<0.01)$ levels of IgG $2 b$ antibody at 3,7 and 22 weeks p.i. were found in mice given live $\mathrm{A} / \mathrm{HK} / 68$ than in all other groups. The greatest IgG3 antibody levels were also observed at all times in mice infected with live virus (fig. $2 \mathrm{~d}$ ), although the levels of this subclass of antibody (and IgG2a antibody) promoted by the $\mathrm{A} / \mathrm{HK} / 68$ subunit ISCOM preparation were higher than the other subunit preparations.

\section{Nasal wash IgG and IgA antibody responses to immunisation}

The nasal wash IgG antibody responses of mice at 7 and 22 weeks p.i. are shown in fig. 3a. All groups of 

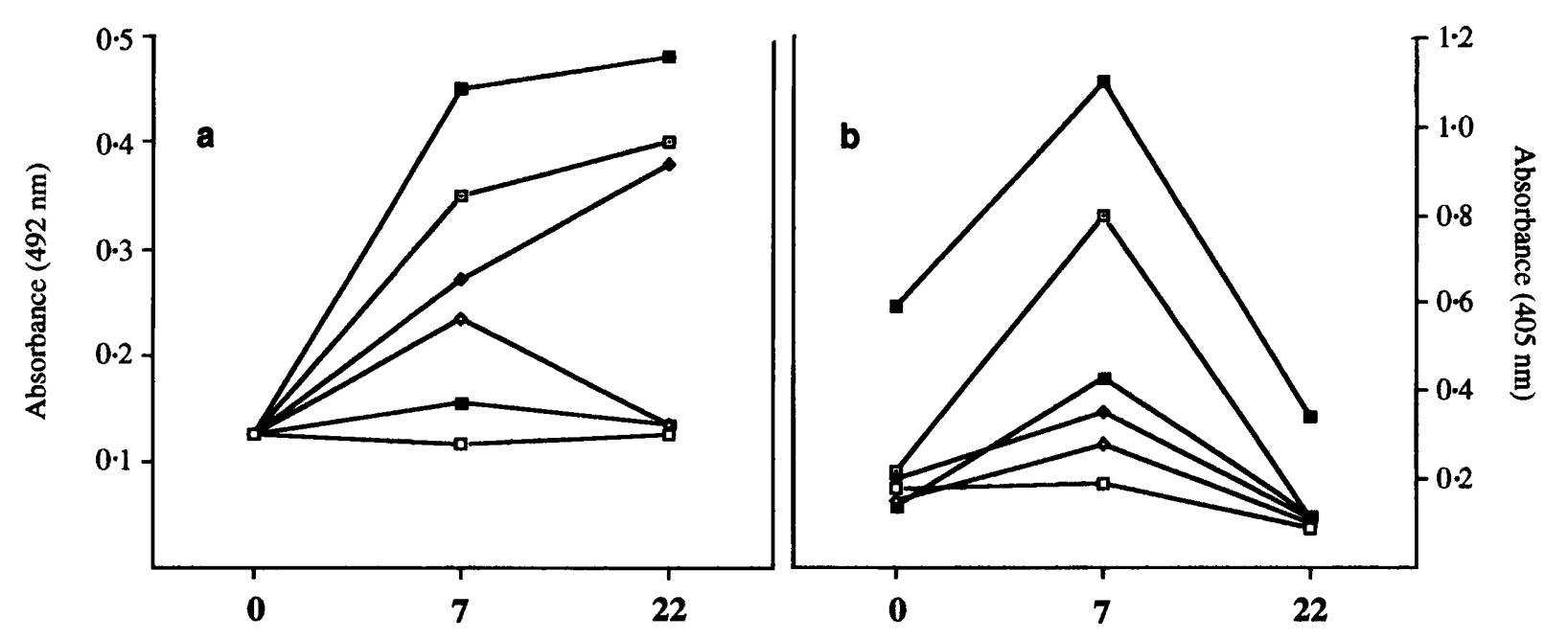

Weeks after immunisation

Fig. 3. Nasal wash IgG (a) and IgA (b) antibody responses of mice to immunisation with influenza A/HK/68 subunit preparations or live virus. $-\square-$ Subunits with ISCOMs; $\square-$ subunits with liposomes; - - - subunits with FCA; $-\diamond-$ subunits alone; $\square-\mathrm{A} / \mathrm{HK} / 68$ live virus; $\square \square-\mathrm{PBS}$.

mice showed the presence of nasal wash IgG antibody at 7 weeks, with the highest titres in those given live virus or ISCOM vaccine preparation; significantly lower levels were found in mice given subunits with FCA, as liposomes, or as an aqueous preparation. However, although the levels of nasal wash $\operatorname{IgG}$ declined at 22 weeks in mice immunised with aqueous subunits, or subunits with FCA, there was an increase in these antibody levels at this time in animals that had received live virus, subunits with ISCOMs or subunits with liposomes (fig. 3a).

In contrast, peak titres of nasal wash IgA were reached for all groups at 7 weeks p.i. and declined sharply by 22 weeks (fig. 3b). At 7 weeks, a significantly greater level of nasal wash IgA was found in mice given live virus than in all other groups $(\mathrm{p}<0.01)$; mice that had received subunits formulated as ISCOMs had nasal wash IgA levels at this time significantly greater than those observed in mice immunised with all other subunit vaccine preparations (fig. $3 b$ ).

\section{Serum and nasal wash antibody levels and protection against homologous virus challenge}

At 3, 7 and 22 weeks p.i., five mice from each group were inoculated intranasally with $10^{3 \cdot 0} \mathrm{MID}_{50}$ of live influenza $\mathrm{A} / \mathrm{HK} / 68$ virus; 3 days later, nasal washes and lung homogenates from each animal were tested for virus. The results are presented in table I together with the mean serum IgG subclass levels and mean nasal wash IgG and IgA levels for each group at each time. At 3 weeks p.i., virus was recovered from the nasal washes of all animals, except two of five mice immunised initially with live virus. Although estimations of nasal wash IgG levels were not performed at 3 weeks, it is of interest to note that the mean nasal wash IgA level was significantly greater in the group that had received live virus than in any other; furthermore, the serum IgG1 and IgG2a subclass antibody levels in mice given live virus initially were lower than, or equivalent to, those elicited by subunit preparations administered as liposomes or ISCOMs, yet animals given these preparations showed no evidence of protection in the upper respiratory tract (table Ia).

Protection in the lower respiratory tract at 3 weeks p.i., as evidenced by lack of recovery of virus from lung homogenates, was observed in three of five mice that had received either the subunit ISCOM preparation or live virus (table Ia); both groups had significantly greater serum levels of IgG2a, IgG2b and IgG3, but not IgG1, than all other groups. Nasal wash IgA levels were similar in those groups immunised with subunits administered as ISCOMs or liposomes, yet no protection was found in mice given the latter preparation at 3 weeks p.i. (table Ia). One of five mice given aqueous subunit preparations showed evidence of protection against homologous virus challenge in the lower respiratory tract; this individual mouse was found to have a serum IgG2a subclass antibody level of 0.79 , significantly greater than that of the other four animals in this group, whose mean IgG2a antibody titre was 0.55 . However, there were no significant differences between the IgA, IgG1, IgG2b and IgG3 levels.

At 7 weeks p.i., the level of immunity had increased. Individual mice in two groups-those given live virus or subunit ISCOMs-showed protection in the upper respiratory tract (table Ib); both groups had nasal wash $\operatorname{IgA}$ and IgG levels significantly greater than those of all other groups. The subclass IgG levels in the sera of these mice were also greater, although not always significantly so, than those of all other groups. Protection was also observed in the lower respiratory tract in some mice from all immunised groups, although the greatest incidence of protection $(80 \%)$ was in mice given either live virus or the subunit ISCOM vaccine. As at 3 weeks p.i., the levels of serum 
Table I. Serum IgG subclass and nasal wash IgA and IgG antibody responses to immunisation with influenza A/HK/68 subunit preparations or live virus at (a) 3, (b) 7 and (c) 22 weeks p.i.

\begin{tabular}{|c|c|c|c|c|c|c|c|c|c|}
\hline \multirow{2}{*}{$\begin{array}{l}\text { Preparation } \\
\text { administered }\end{array}$} & \multirow{2}{*}{ Route } & \multicolumn{4}{|c|}{ Mean serum IgG subclass (SD) } & \multirow{2}{*}{$\begin{array}{c}\text { NW IgG } \\
\text { Mean (SD) }\end{array}$} & \multirow{2}{*}{$\begin{array}{c}\text { NW IgA } \\
\text { Mean (SD) }\end{array}$} & \multicolumn{2}{|c|}{ Protection $(\%)$} \\
\hline & & IgG1 & $\operatorname{IgG} 2 \mathrm{a}$ & $\operatorname{IgG} 2 b$ & IgG3 & & & URT* & Lungs \\
\hline \multicolumn{10}{|l|}{$\mathbf{a}$} \\
\hline Liposomes & i.m. & $0.99(0.12)$ & $0.53(0.15)$ & $0.42(0.12)$ & $0.38(0.08)$ & & $0.20(0.09)$ & $0 / 5(0)$ & $0 / 5(0)$ \\
\hline ISCOMs & i.m. & $1.20(0.13)$ & $0.80(0.12)$ & $0.77(0 \cdot 14)$ & $0.58(0.13)$ & & $0.22(0 \cdot 10)$ & $0 / 5(0)$ & $3 / 5(60)$ \\
\hline Subunits & i.m. & $0.68(0.18)$ & $0.53(0.17)$ & $0.46(0.16)$ & $0.39(0.11)$ & & $0.15(0.02)$ & $0 / 5(0)$ & $1 / 5(20)$ \\
\hline PBS & i.m. & $0.08(0.03)$ & $0.08(0.01)$ & $0.09(0.08)$ & $0.14(0.01)$ & & $0.18(0.05)$ & $0 / 5(0)$ & $0 / 5(0)$ \\
\hline $\mathrm{FCA}$ & s.c. & $0.69(0.09)$ & $0.58(0.26)$ & $0.21(0.06)$ & $0.20(0.05)$ & & $0.140 .02)$ & $0 / 5(0)$ & $0 / 5(0)$ \\
\hline Live virus & i.n. & $0.96(0.09)$ & $0.84(0.08)$ & $1.00(0.15)$ & $0.68(0.11)$ & & $0.59(0.20)$ & $2 / 5(40)$ & $3 / 5(60)$ \\
\hline \multicolumn{10}{|l|}{ b } \\
\hline Liposomes & i.m. & $0.84(0 \cdot 20)$ & $0.60(0.27)$ & $0.48(0.17)$ & $0.43(0.8)$ & $0.27(0 \cdot 14)$ & $0.35(0.18)$ & $0 / 5(0)$ & $1 / 5(20)$ \\
\hline ISCOMs & i.m. & $1 \cdot 10(0.23)$ & $1 \cdot 10(0 \cdot 25)$ & $0.70(0.30)$ & $0.57(0.19)$ & $0.35(0 \cdot 18)$ & $0.80(0.36)$ & $2 / 5(40)$ & $4 / 5(80)$ \\
\hline Subunits & i.m. & $0.81(0 \cdot 16)$ & $0.74(0.15)$ & $0.63(0.15)$ & $0.48(0.10)$ & $0 \cdot 23(0 \cdot 15)$ & $0.28(0.04)$ & $0 / 5(0)$ & $1 / 5(20)$ \\
\hline PBS & i.m. & $0.12(0.02)$ & $0.09(0.03)$ & $0.04(0.01)$ & $0.11(0.05)$ & $0 \cdot 11(0 \cdot 01)$ & $0.19(0.03)$ & $0 / 5(0)$ & $0 / 5(0)$ \\
\hline FCA & s.c. & $1 \cdot 10(0 \cdot 13)$ & $1.00(0 \cdot 30)$ & $0.66(0.30)$ & $0.36(0.08)$ & $0.15(0.04)$ & $0.43(0.37)$ & $0 / 5(0)$ & $2 / 5(40)$ \\
\hline Live virus & i.n. & $1 \cdot 20(0 \cdot 10)$ & $1 \cdot 40(0 \cdot 10)$ & $1 \cdot 10(0.09)$ & $0.90(0.16)$ & $0.45(0 \cdot 27)$ & $1 \cdot 10(0 \cdot 23)$ & $2 / 5(40)$ & $4 / 5(80)$ \\
\hline \multicolumn{10}{|l|}{$\mathbf{c}$} \\
\hline Liposomes & i.m. & $0.45(0.70)$ & $0.36(0.17)$ & $0.17(0.06)$ & $0.08(0.03)$ & $0 \cdot 38(0 \cdot 20)$ & $0 \cdot 11(0 \cdot 01)$ & $0 / 5(0)$ & $0 / 5(0)$ \\
\hline ISCOMs & i.m. & $1 \cdot 00(0 \cdot 11)$ & $1 \cdot 20(0.09)$ & $0.46(0 \cdot 19)$ & $0.18(0.09)$ & $0.40(0.21)$ & $0.11(0.01)$ & $0 / 5(0)$ & $2 / 5(40)$ \\
\hline Subunits & i.m. & $0.43(0.21)$ & $0.53(0.19)$ & $0.16(0.07)$ & $0.11(0.02)$ & $0.19(0.12)$ & $0.10(0.01)$ & $0 / 5(0)$ & $1 / 5(\mathbf{2 0})$ \\
\hline PBS & i.m. & $0.08(0.01)$ & $0.04(0.02)$ & $0.05(0.01)$ & $0.05(0.01)$ & $0 \cdot 12(0 \cdot 02)$ & $0.09(0.01)$ & $0 / 5(0)$ & $0 / 5(0)$ \\
\hline $\mathrm{FCA}$ & s.c. & $0.83(0.17)$ & $0.54(0.17)$ & $0.14(0.09)$ & $0.10(0.04)$ & $0.13(0.02)$ & $0.12(0.01)$ & $0 / 4(0)$ & $1 / 5(20)$ \\
\hline Live virus & i.n. & $1 \cdot 10(0 \cdot 20)$ & $1 \cdot 40(0 \cdot 10)$ & $0.80(0.33)$ & $033(0 \cdot 12)$ & $0.48(0.19)$ & $0.34(0.08)$ & $2 / 5(40)$ & $3 / 5(60)$ \\
\hline
\end{tabular}

Number of sera tested for IgG subclasses was 18, 13 and eight for each preparation at 3, 7 and 22 weeks respectively. Number of lungs tested for virus or nasal washes tested for virus and for IgA and IgG antibodies was five for each preparation. NW, nasal wash; URT, upper respiratory tract; i.n., intranasal; i.m., intramuscular; s.c., subcutaneous.

* Number of mice showing no evidence of virus in nasal wash or lung/total $(\%)$

IgG2a, IgG2b and IgG3 and nasal wash IgG were all higher, although not always significantly so, in these two groups than in all others. The serum IgG1 subclass levels at 7 weeks in mice given subunits with FCA or as ISCOMs were identical, yet the incidence of protection in the lungs in the former group was only half that in the latter (table Ib).

For mice challenged at 22 weeks p.i. (table Ic), the results were similar to those at 3 weeks. Thus, only in mice immunised with live virus was there any protection in the upper respiratory tract, and, as at 3 weeks, this was associated with a significantly higher level of nasal wash IgA. Furthermore, significantly higher or relatively high levels of all subclass antibodies were found in sera from mice given live virus initially, and this group also showed the greatest incidence of protection in the lower respiratory tract (table Ic) at 22 weeks p.i., although all groups of mice, except those that had received subunits in a liposome formulation, showed some incidence of protection at this site. Compared to the effects of the subunit ISCOMs preparation, which elicited protection in two of five mice at 22 weeks, all serum IgG subclass antibody levels in mice given the subunit liposome preparation were significantly lower. However, the nasal wash IgG antibody levels were identical in both groups.

\section{Protection against heterologous $A /$ Sichuan/87 virus infection}

In a further experiment under conditions essentially similar to those employed in the first study, 10-12 mice from groups of 18 given live $\mathrm{A} / \mathrm{HK} / 68$ influenza virus intranasally, or immunised with $\mathrm{A} / \mathrm{HK} / 68$ subunits administered as an aqueous preparation, as ISCOMs, or with FCA, or given PBS alone by parenteral routes, were challenged $24 \mathrm{~h}$ after collection of blood at 5 weeks p.i. with $10^{3.0} \mathrm{MID}_{50}$ of either $\mathrm{A} / \mathrm{HK} / 68$ virus or the heterologous A/Sichuan/87 (H3N2) strain by the intranasal route. Half the animals received the former and half the latter virus strain. Nasal washes and lung homogenates obtained from these mice 3 days later were tested for the presence of virus. All sera were assayed for IgA and subclass IgG antibodies and nasal washes were assayed for IgA antibodies. The results (table II) show that none of the immunising preparations, including live virus, induced protection against homologous $\mathrm{A} / \mathrm{HK} / 68$ virus in the nasal passages of mice. In contrast, both live $\mathrm{A} / \mathrm{HK} / 68$ virus and the $\mathrm{A} / \mathrm{HK} / 68$ subunit ISCOM preparation had elicited protection in the lower respiratory tract of a proportion of animals. These results are essentially similar to those observed at 3 weeks p.i. in the experiments already described. Furthermore, with respect to levels of serum IgA and IgG in each subclass and of nasal wash $\operatorname{IgA}$, mice immunised with live virus initially showed significantly greater responses than those elicited by all other groups. The levels of these antibodies induced by the ISCOM preparation were also higher than those induced by other subunit preparations. Essentially similar findings were obtained with mice challenged with the heterologous A/Sichuan/87 influenza virus strain; protection was primarily found in the lower respiratory tract, and was 
Table II. Serum IgA and IgG subclass and nasal wash IgA antibody responses to immunisation with influenza A/HK/68 subunit preparations or live virus at 5 weeks p.i. and protection against (a) homologous and (b) heterologous challenge infection.

\begin{tabular}{|c|c|c|c|c|c|c|c|c|c|}
\hline \multirow{2}{*}{$\begin{array}{l}\text { Preparation } \\
\text { administered }\end{array}$} & \multirow{2}{*}{ Route } & \multicolumn{4}{|c|}{ Mean serum IgG subclass (SD) } & \multirow{2}{*}{$\begin{array}{l}\text { Serum IgA } \\
\text { Mean (SD) }\end{array}$} & \multirow{2}{*}{$\begin{array}{c}\text { NW IgA } \\
\text { Mean (SD) }\end{array}$} & \multicolumn{2}{|c|}{ Protection } \\
\hline & & IgG1 & IgG2a & $\operatorname{IgG} 2 b$ & IgG3 & & & URT* & Lungs \\
\hline \multicolumn{10}{|l|}{ a } \\
\hline FCA & s.c. & $0 \cdot 61(0 \cdot 18)$ & $0 \cdot 34(0 \cdot 16)$ & $0.25(0.17)$ & $0 \cdot 16(0 \cdot 05)$ & $0 \cdot 10(0.01) \dagger$ & $0.14(0.03) \dagger$ & $0 / 5(0)$ & $0 / 5(0)$ \\
\hline ISCOMs & i.m. & $0.77(0.21)$ & $0.39(0.21)$ & $0.41(0.29)$ & $0.33(0.06)$ & $0.13(0.03)$ & $0.39(0.11)$ & $0 / 6(0)$ & $3 / 6(50)$ \\
\hline Subunits & i.m. & $0.42(0.10)$ & $0.26(0.07)$ & $0.17(0.05)$ & $0.16(0.05)$ & $0.09(0.01)$ & $0.21(0.12)$ & $0 / 6(0)$ & $0 / 6(0)$ \\
\hline Live virus & i.n. & $1 \cdot 10(0.07)$ & $1.00(0.08)$ & $0.92(0.15)$ & $0.65(0.18)$ & $0.37(0.06)$ & $0.97(0.28)$ & $0 / 6(0)$ & $5 / 6(83)$ \\
\hline PBS & i.m. & $0.04(0.01)$ & $0.05(0.02)$ & $0.04(0.02)$ & $0.05(0.01)$ & $0.09(0.01) \dagger$ & $0 \cdot 16(0 \cdot 10)_{+}^{+}$ & $0 / 5(0)$ & $0 / 6(0)$ \\
\hline \multicolumn{10}{|l|}{ b } \\
\hline FCA & s.c. & $0.32(0.19)$ & $0.23(0.14)$ & $0.16(0.09)$ & $0.14(0.06)$ & $0.12(0.02)$ & $0.26(0.15)$ & $0 / 6(0)$ & $0 / 6(0)$ \\
\hline ISCOMs & i.m. & $0.42(0.10)$ & $0.36(0.07)$ & $0.23(0.05)$ & $0.36(0.05)$ & $0 \cdot 12(0.01)$ & $0.45(0.14)$ & $0 / 6(0)$ & $2 / 6$ (34) \\
\hline Subunits & i.m. & $0.34(0.15)$ & $0.27(0.07)$ & $0.20(0.07)$ & $0.16(0.05)$ & $0.10(0.02)$ & $0.20(0 \cdot 10)$ & $0 / 6(0)$ & $0 / 6(0)$ \\
\hline Live virus & i.n. & $1 \cdot 10(0 \cdot 10)$ & $1 \cdot 10(0.08)$ & $0.72(0.18)$ & $0.59(0.25)$ & $0.39(0.03)$ & $0.91(0.19)$ & $1 / 6(17)$ & $4 / 6(67)$ \\
\hline PBS & i.m. & $0.05(0.02)$ & $0.06(0.02)$ & $0.04(0.03)$ & $0.05(0.02)$ & $0.09(0.01)$ & $0.13(0.03)$ & $0 / 6(0)$ & $0 / 6(0)$ \\
\hline
\end{tabular}

Number of samples tested was six; $\ddagger$ denotes that the number was four; †denotes the number was five. NW, nasal wash; URT, upper respiratory tract; i.n., intranasal; i.m., intramuscular; s.c., subcutaneous.

* Number of mice showing no evidence of virus in nasal wash or lung/total $(\%)$.

confined to those mice immunised with live A/HK/68 virus or $\mathrm{A} / \mathrm{HK} / 68$ subunits formulated into ISCOMs. Greatest IgA and subclass IgG antibody levels were also found in mice immunised with these two preparations.

\section{Discussion}

Numerous studies have indicated that immunity against influenza is directly related to the serum antibody response to the virus $\mathrm{HA}$, and that serum haemagglutination-inhibition (HI) titres of 30-40 indicate protection. ${ }^{1}$ However, although existing commercially available saline subunit vaccines induce high levels of serum antibody to the virus HA, the level of immunity to subsequent infection has been, and remains, disappointingly low. ${ }^{2,21,22}$ The innate reactogenicity of the influenza virus $\mathrm{HA}^{4}$ prohibits an increase in the HA content of vaccines, but one strategy to enhance the immune response would be to use relatively small quantities of virion subunits in conjunction with a potent delivery system. Several such systems, including liposomes, ${ }^{7}$ various formulations incorporating muramyl di- or tripeptides ${ }^{8,9}$ and ISCOMs, ${ }^{10,11}$ are currently undergoing intensive investigation. For each of these adjuvant systems, enhanced immune responses have been reported in comparison to aqueous influenza virus vaccine preparations. In contrast, comparative studies of the immune-enhancing potential of different adjuvant systems are sparse, but such studies should be undertaken to identify the most effective and appropriate adjuvant.

In the present study, the local and systemic humoral immune responses and the protection against challenge virus infection were assessed in mice immunised with influenza virus subunit preparations incorporated into ISCOMs or liposomes; the immune responses and protection afforded by these adjuvanted vaccine preparations were compared to those induced by aqueous subunit preparation, the subunits with FCA and live virus infection. These latter preparations were included to indicate baseline values of immunity and protection (aqueous subunit preparation) and desirable levels of immunity and protection (live virus infection), since studies in man indicate that live influenza virus vaccines confer greater immunity than inactivated preparations. ${ }^{13,23}$ The inclusion of FCA provided an indication of the levels of immunity and protection achievable with an inactivated antigen by using an adjuvant which, although not suitable for use in man, ${ }^{24}$ is reported to have potent, immune-enhancing properties. ${ }^{25}$

The results indicate that infection of mice with live influenza virus induces the greatest and most persisting antibody responses and protection at both local and systemic levels, confirming previous studies. $^{12}$ Although none of the inactivated preparations used elicited equivalent immunity and protection, influenza subunits incorporated into ISCOMs proved the most effective in these respects. More particularly, the subunit ISCOM vaccine was superior to subunits incorporated with FCA, and to the liposome preparation-the latter preparation was, in turn, the best of four influenza subunit-liposome formulations assessed in previous studies. ${ }^{26}$

The high degree of protection observed in mice given live virus infection, and its persistence, can be equated with local and systemic humoral immune responses. Thus, local IgA and IgG antibody levels, and serum IgG antibody levels, particularly the IgG2a subclass, achieved either higher levels or persisted at relatively high levels for longer, or both, following live virus infection than was observed for these responses after immunisation with any of the inactivated subunit 
preparations. Nevertheless, these responses were most closely matched in mice immunised with the ISCOM subunit preparation. In particular, serum IgG2a responses were high and persisted well in these animals and this IgG subclass has been reported to have high influenza virus neutralising capacity ${ }^{20}$ and also properties of activating complement ${ }^{27}$ and mediating phagocytosis $^{28}$, properties suggesting interreaction of such antibody with aspects of cellular immune mechanisms. As reported previously, nasal wash IgA levels at 7 weeks p.i. are also relatively high in mice immunised with the influenza virus subunit ISCOM preparation. ${ }^{11}$

These studies comparing the nature of the humoral immune responses and protection against challenge

\section{References}

1. Potter CW. Inactivated influenza virus vaccines. In: Beare AS (ed) Basic and applied influenza research. Boca Raton, FL, CRC Press. 1982: 119-158.

2. Hobson D. Assessment of the efficacy of influenza vaccines against natural challenge. In: Perkins FT, Regamey RH, Hennessey W (eds) International symposium on immunity to infections of the respiratory system in man and animals. Dev Biol Stand 1975; 28: 285-294.

3. Potter CW, Oxford JS. Determinants of immunity to influenza infection in man. Br Med Bull $1979 ; 35: 69-75$.

4. Pickering JM, Smith $H$, Sweet $C$. Influenza virus pyrogenicity: central role of structural orientation of virion components and involvement of viral lipid and glycoproteins. $J$ Gen Virol 1992; 73: 1345-1354.

5. Katz JM, Webster RG. Efficacy of inactivated influenza A virus (H3N2) vaccines grown in mammalian cells or embryonated eggs. J Infect Dis 1989; 160: 191-198.

6. Bombord R. Immunomodulation by adjuvants. In: Dimmock NJ, Griffiths PD, Madeley CR (eds) Control of virus diseases. Cambridge, Cambridge University Press. 1990: 315-339.

7. Gregoriadis G. Immunological adjuvants: a role for liposomes Immunol Today 1990; 11: 89-97.

8. Tsujimoto M, Kotani S, Kinoshita F et al. Adjuvant activity of 6-0-acyl-muramyldipeptides to enhance primary cellular and humoral responses in guinea pigs: adaptability to various vehicles and pyrogenicity. Infect Immun 1986; 53: 511-516.

9. Nerome K, Yoshioka Y, Ishida M et al. Development of a new type of influenza subunit vaccine made by muramyldipeptide-liposome: enhancement of humoral and cellular immune responses. Vaccine 1990; 8: 503-509.

10. Lovgren K, Kaberg H, Morein B. An experimental influenza subunit vaccine (ISCOM): induction of protective immunity to challenge infection in mice after intranasal or subcutaneous administration. Clin Exp Immunol 1990;82 435-439.

11. Ben Ahmeida ETS, Jennings R, Erturk M, Potter CW. The IgA and subclass IgG responses and protection in mice immunised with influenza antigens administered as ISCOMS, with FCA, ALH or as infectious virus. Arch Virol 1992; 125: $71-86$.

12. Murphy BR, Nelson DL, Wright PF, Tierney EL, Phelan MA, Channock RM. Secretory and systemic immunological response in children infected with live attenuated influenza A virus vaccines. Infect Immun 1982; 36: 1102-1108.

13. Clements ML, Murphy BR. Development and persistence of local and systemic antibody responses in adults given live attenuated or inactivated influenza A virus vaccine. J Clin Microbiol 1986; 23: 66-72.

14. Crawford CR, Mukhlis FA, Jennings R, Oxford JS, Hockley DJ, Potter CW. Use of zwitterionic detergent for the preparation of an influenza virus vaccine. 1. Preparation and characterization of disrupted virions. Vaccine 1984; 2 : 193-198. infection induced in mice immunised with several types of vaccine preparation show that the responses elicited by an ISCOM subunit antigen preparation most closely approach those seen after live virus infection, and confirm other studies suggesting that viral antigens incorporated into ISCOMs represent a potent immuno-enhancing system. ${ }^{10,29-31}$

However, the relative merits of an influenza subunit antigen ISCOM preparation in comparison to immune-enhancing adjuvant systems other than those assessed here remain to be determined.

The authors are grateful to Ms Pauline Whitaker for secretarial assistance. This work was supported partially by a grant to E.T.S.B.-A. from the Government of Libya.

15. Wood JM, Schild GC, Newman RW, Seagrott V. Application for an improved single-radial-immunodiffusion technique for the assay of haemagglutinin antigen content of whole virus and subunit influenza vaccines. In: Perkins FT, Regamey RH (eds) International symposium on influenza immunisation. Dev Biol Stand 1977; 39: 193-200.

16. Bradford MM. A rapid and sensitive method for the quantitation of microgram quantities of protein utilizing the principle of protein-dye binding. Anal Biochem 1976; 72: 248-254.

17. Gregoriadis G, Tan L, Ben-Ahmeida ETS, Jennings R. Liposomes enhance the immunogenicity of reconstituted influenza virus $\mathrm{A} / \mathrm{PR} / 8$ envelopes and the formation of protective antibody by influenza virus A/Sichuan/87 (H3N2) surface antigen. Vaccine 1992; 10: 747-753.

18. Jennings R, Denton MD, Potter CW. The hamster as an experimental animal for the study of influenza. I. The role of antibody in protection. Med Microbiol Immunol 1976; 162: $217-226$.

19. Jennings R, Smith T, Potter CW. Use of the enzyme-linked immunosorbent assay (ELISA) for the estimation of serum antibodies in an influenza virus vaccine study. Med Microbiol Immunol 1981; 169: 247-258.

20. Hocart MJ, Mackenzie JS, Stewart GA. The immunoglobulin $G$ subclass responses of mice to influenza $A$ virus: the effect of mouse strain, and the neutralizing abilities of individual protein-A-purified subclass antibodies. J Gen Virol 1989; 70: 2439-2448.

21. Gross PA, Weksler ME, Quinnan GV, Douglas RG, Gaerlan PF, Denning CR. Immunization of elderly people with two doses of influenza vaccine. J Clin Microbiol 1987; 25: 1763-1765.

22. Zuckerman M, Oxford J, Wood J, Taylor J. The influenza A (H3N2) component of recommended vaccine induces antibody to the current virus. Lancet $1990 ; 1: 179-180$.

23. Johnson PR, Feldman S, Thompson JM, Mahoney JD, Wright PF. Immunity to influenza A virus infection in young children: a comparison of natural infection, live coldadapted vaccine, and inactivated vaccine. J Infect Dis 1986 ; 154: 121-127.

24. Edelman R. Vaccine adjuvants. Rev Infect Dis $1980 ; 2 \cdot 370-383$.

25. Potter CW, Jennings R, McLaren C. Immunity to influenza in ferrets. VI. Immunization with adjuvanted vaccines. Arch. fur die gesamte Virusforschung 1973; 42: 285-296.

26. Ben Ahmeida ETS, Jennings R, Tan L, Gregoriadis G, Potter $\mathrm{CW}$. The subclass IgG responses of mice to influenza surface proteins formulated into liposomes. Antiviral Res in press.

27. Spiegelberg HL. Biological activities of immunoglobulins of different classes and subclasses. Adv Immunol 1974; 19 . 259-294.

28. Wiener E. The ability of IgG subclasses to cause the elimination of targets in vivo and to mediate their destruction by phagocytosis/cytolysis in vitro. In: Shakib F (ed) The human IgG subclasses: molecular analysis of structure, function and regulation. Oxford, Pergamon Press. 1990: $135-160$. 
29. Jones PD, Tha-Hla R, Morein B, Lovgren K, Ada GL. Cellular immune responses in the murine lung to local immunization with influenza $\mathbf{A}$ virus glycoproteins in micelles and immunostimulatory complexes(ISCOMs). ScandJImmunol 1988; 27: 645-652.

30. Takahashi H, Takeshita T, Morein B, Putney S, Germain RN,
Berzofsky JA. Induction of $\mathrm{CD}^{+}$cytotoxic $\mathrm{T}$ cells by immunization with purified HIV-1 envelope protein in ISCOMs. Nature 1990; 344: 873-875.

31. Erturk M, Phillpotts RJ, Welch MJ, Jennings R. Efficacy of HSV-1 ISCOM vaccine in the guinea-pig model of HSV-2 infection. Vaccine 1991; 9: 728-734. 